\title{
Optimal Endogenous Tariffs with Implicit Campaign Contributions
}

\author{
Gaël Lagadec \\ University of New Caledonia (LARJE), Nouméa, New Caledonia \\ Email: lagadec@univ-nc.nc \\ Received 5 February 2014; revised 5 March 2014; accepted 25 March 2014 \\ Copyright @ 2014 by author and Scientific Research Publishing Inc. \\ This work is licensed under the Creative Commons Attribution International License (CC BY). \\ http://creativecommons.org/licenses/by/4.0/

(c) (i) Open Access

\begin{abstract}
This article proposes a model of endogenous protection by integrating informed and non-informed voters in the population. The model also distinguishes between interest groups and pressure groups, by considering that the members of one interest group do not necessarily organize as a pressure group (lobby). The endogenous tariff stemming from the model is an increasing function of the relative influence of the lobby, and the aforementioned function itself increases in accordance with the part of non-informed voters. This framework avoids formalizing contributions. It also permits to show that the conditions of the lobbying's efficiency depend on the nature of the free rider comportment of the interest group members.
\end{abstract}

\section{Keywords}

Lobbies, Voters, Endogenous Tariffs

\section{Introduction}

Taking into account the interactions between politics and economy started with Buchanan and Tullock's work in 1962 [1]. The reality of these interactions has often been highlighted since then and a lot of articles have shown that the activity of organized groups motivated by rent seeking had highly detrimental consequences on the economy ([2] [3] for example).

A lobby (or "pressure group") is first of all a group of interest (a group of individuals sharing a common individual interest) but, unlike the latter, the group members have rallied to organize a collective action in order to pursue their common individual interest collectively ${ }^{1}$.

The lobbying models have often taken into account two goals that are partly exchangeable for the politician, namely the contributions received from private interests and social welfare. Peltzman ([5]) initiated this process

${ }^{1}$ See [4], for the different basic factors needed to transform an interest group into a pressure group. 
and numerous writers followed suit, such as Hillman ([6]) or, more recently, Grossman and Helpman's ([7] [8]) model, which seemed particularly strong ([9], for example), became the reference in terms of endogenous protection.

Within this framework, the existence of non-informed voters, i.e. voters whose preference can be influenced, is an inescapable hypothesis (see [10]). Indeed were the voters not easily influenced, the campaigns costs would be inefficient and the contributions as well as the contributors would be unjustified.

The presence of non-informed voters is most often implicit in the literature. It serves as backdrop to the analysis, as in Grossman and Helpman.

So this article aims at proposing a model of endogenous protection integrating explicitly the parts of informed and non-informed voters. We show that taking into account the distinction between informed and non-informed voters explicitly allows thinking in terms of implicit contributions, which is to determine the endogenous tariff, by making the part of informed voters an inverted proxy of the lobbies' influence (their interests being taken into account via the contributions given). It's no longer necessary to optimize an objective function including a weighted sum of social welfare and contributions in order to determine the endogenous tariff applied.

From this point, optimal tariffs for sub-groups of the population are calculated: for the lobbies and the rest of the population (including, in an original way, the owners of specific factors who choose not to join the lobbythose members remain a part of a pressure group but do not take part in collective action). Then these tariffs allow deducing the endogenous tariff actually applied according to the part of informed voters.

The trade policy depends strongly on the importance of informed voters in the global population. The wider the awareness of economic and political mechanisms in the population, the more the given country will be seen as a proponent of free-trade.

In our approach, the contributions paid throughout the election process do not make an explicit variable of the model. If this may seem as a weakness in open transparent systems where contributions are publicly known, one has to admit that opacity most often prevails in this field.

Adopting our way of thinking offers an alternative to current approaches better befitting some political systems in which the links between candidates and lobbies are a priori forbidden or not really transparent ${ }^{2}$.

In Section 2, we will present the model; in Section 3, we will solve it and in Section 4, we will discuss the results.

\section{The Model}

We distinguish five kinds of actors: the informed voters (not influenceable), the non informed voters, the owners of specific factors (and inside this group, those who are engaged into lobbying action and those who simply remain part of an interest group), and the government (or "incumbent", since our approach is not an electoral competition approach).

The Figure 1 below makes it clear how these different actors connect together.

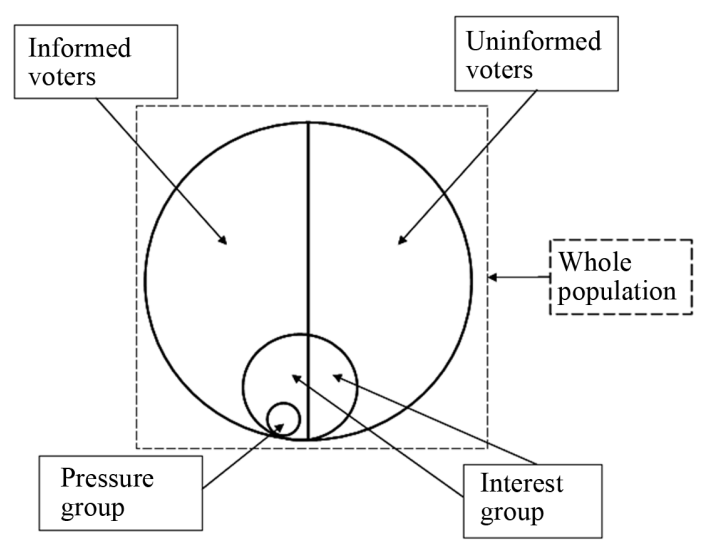

Figure 1. Different kinds of actors.

\footnotetext{
${ }^{2}$ The USA is the country where the economic and political processes are most transparent (see for instance [11], capable to carry out tests on the contributions paid by American lobbies since a century). Conversely the lack of information on these relations is particularly pronounced in developing countries (on these questions of data and methodology see [12]).
} 
The incumbent has an objective function $(G)$ with respect to two variables: the lobby's welfare $\left(W^{l}\right)$ and the rest of the population's welfare $\left(W^{P}\right)$. Following [5] and [7] [8], the incumbent has such a function for each economic sector. This function $G=G\left(W^{P}, W^{l}\right)$ is supposed to be of linear form, following Grossman and Helpman's standard objective function.

$\alpha$ is the part of informed voters in the global population. The weaker $\alpha$, the more influential the lobbies ${ }^{3}$. The population is normalized to 1 .

Individuals have identical additive utility functions in the shape:

$$
U_{t}=\theta_{Z}+\sum U\left(\theta_{X_{i}}\right)
$$

$\theta_{Z}$ is consumption of good $Z$, which serves as standard with a domestic and international price normalized to 1 . $\theta_{X_{i}}$ is the consumption of good $X_{i}(i=1,2, \cdots, n)$.

The utility functions are differentiable, rising and strictly concave. The standard good is produced from labor only (a work unit produces a good unit). The other goods are produced each by labor and a specific factor with constant returns to scale. All prices are measured in accordance with the standard. Since the domestic price of good $Z$ has been normalized to one, the competitive wage must equal one in any equilibrium in which this good is produced ([8], for example).

We extend Grossman and Helpman's standard model so as to consider that the government exerts trade policies (creating a gap between domestic and international prices) for political support motives.

We consider $n$ economic sectors.

$P_{i}=\left(P_{1}, P_{2}, \cdots, P_{n}\right)$ is the vector of domestic prices of non standard goods $\pi_{i}=\left(\pi_{1}, \pi_{2}, \cdots, \pi_{n}\right)$ is the vector of international prices of non standard goods. $r_{i}=\left(r_{1}, r_{2}, \cdots, r_{n}\right)$ is the vector of trade taxes (a tariff on imports or a subsidy for exports if superior to 1 ). So for each sector $i$ we have: $P_{i}=\pi_{i} r_{i}$.

We have $n$ interest groups (potential lobbies, corresponding to the factors owners); only one part of these groups is capable to overcome the problem of collective action ([14]) and to become lobbies ${ }^{4}$.

The consumer surplus is the variable chosen to appreciate the voters' welfare:

$$
S\left(P_{i}\right)=\sum_{i} U\left(d_{i}\left(P_{i}\right)\right)-\sum_{i} P_{i} d_{i}\left(P_{i}\right) \text { and: } S\left(r_{i} \pi_{i}\right)=\sum_{i} U\left(d_{i}\left(r_{i} \pi_{i}\right)\right)-\sum_{i} r_{i} \pi_{i} d_{i}\left(r_{i} \pi_{i}\right) \text {, with } d_{i} \text { the demand in }
$$
good $i$.

The tax policy also determines the tax revenue $(R)$. We write that $q_{i}$ represents the produced domestic quantity of output for the sector $i$. We have the tax revenue:

$$
R(r, \pi)=\sum_{i}\left(\left(r_{i}-1\right) \pi_{i}\left(d_{i}\left(r_{i} \pi_{i}\right)-q_{i}\left(r_{i} \pi_{i}\right)\right)\right),
$$

where $d_{i}\left(r_{i} \pi_{i}\right)-q_{i}\left(r_{i} \pi_{i}\right)$ represents the demand minus the production, i.e. the imports $\left(M_{i}\right)$. A customs tariff exists when at least one factor of production specific in the industry is present. The tariff (subsidy) also determines the rent earned from this factor of production. Given $\Pi_{i}\left(P_{i}\right)$ the rent aggregate entailed by tariff (subsidy).

The general welfare $(W)$ is the summation of these three elements to which we add the aggregate labor supply $(L)$ as in the Grossman-Helpman standard model:

$$
W(r, \pi)=L+\sum_{i} \prod_{i}\left(r_{i} \pi_{i}\right)+R(r, \pi)+S(r, \pi)
$$

The right-hand side of this equation represents the sum of labor income (competitive wage being equal to one), profits, tariff revenues and the total consumer surplus (welfare is then expressed in a monetary fashion).

We distinguish several groups within the population (normalized to 1 ). In sector $i, \chi_{i}$ is the part of capital owners (interest group), $\hat{\chi}_{i}$ is the part of capital owners who have overcome the difficulties stemming from

\footnotetext{
${ }^{3}$ According to this typology, the stronger the part of informed voters, the better the situation fits the theorem of the median voter. Conversely the stronger the part of non informed voters, the more present the interest groups ([10], p. 39). How important it is to consider the part of non informed voters is notably illustrated by [13]'s study. The author develops an analysis based on a model close to [7] to analyze the role of the information the voters detain. He shows that the level of information is crucial in the choice politicians in office make to satisfy the interests of the median voters or to get closer to the lobbies by swapping sector policies that favor the lobbies for some funding.

${ }^{4} \mathrm{~A}$ lobby is first of all a group of interest (a group of individuals sharing a common individual interest) but, unlike the lobby, the group members have not rallied to organize a collective action in order to pursue their common individual interest collectively. [4] explains the different basic factors needed to transform an interest group into a pressure group.
} 
collective action (pressure group or "lobby") ${ }^{5}$. We have $\chi_{i}>\hat{\chi}_{i}$. The part of non-organized owners is $\left(\chi_{i}-\hat{\chi}_{i}\right)$ and the population except the lobby is $\left(1-\hat{\chi}_{i}\right)$.

$W_{i}^{l}$ is the lobby's welfare and $W^{p}$ the welfare of the population except the lobby.

The lobby's welfare is expressed as:

$$
W_{i}^{l}(r, \pi)=\hat{\chi}_{i} \cdot L_{i}+\frac{\hat{\chi}_{i}}{\chi_{i}} \cdot \prod_{i}\left(r_{i} \pi_{i}\right)+\hat{\chi}_{i} \cdot[R(r, \pi)+S(r, \pi)]
$$

$L$ represents the supply of labor, $\Pi$ represents the productivity of the specific factor, $R$ represents the tax revenue, and $S$ represents the consumer surplus.

The first term represents the part of labor offer coming from the lobby's members, the second term represents the part of the rent of the specific factor's falling to active members of the interest groups (that is to say to lobby's members), the third terms is the part of consumers surplus and customs revenue falling to the lobby's members.

The population's welfare (except the lobby) is expressed as:

$$
W^{P}(r, \pi)=\sum_{i}\left(\left(1-\hat{\chi}_{i}\right) \cdot L_{i}+\frac{\chi_{i}-\hat{\chi}_{i}}{\chi_{i}} \cdot \Pi_{i}\left(r_{i} \pi_{i}\right)\right)+\left(1-\hat{\chi}_{i}\right) \cdot[R(r, \pi)+S(r, \pi)]
$$

The first whole additive term represents the part of labor offer coming from the population except lobby's members and the part of the rent of the specific factor's falling to the members of the interest groups (and not to lobby's members), the second terms is the part of consumers surplus and customs revenue falling to the population.

\section{Resolution}

\subsection{Optimal Tariff for the Population except the Lobby}

In the typical situation of a sector politically organized since it is in competition with imports, the function is rewritten:

$$
W^{P}(r, \pi)=\left(1-\hat{\chi}_{i}\right) \cdot L_{i}+\frac{\chi_{i}-\hat{\chi}_{i}}{\chi_{i}} \cdot \prod_{i}\left(r_{i} \pi_{i}\right)+\left(1-\hat{\chi}_{i}\right) \cdot\left[\left(r_{i}-1\right) \cdot M_{i}\left(r_{i}\right)+S\left(r_{i}, \pi_{i}\right)\right]
$$

with $M_{i}$ the quantity of imported good $i$.

Remark: for the sake of simplicity from here on we won't indicate indice $i$ for $\chi$ and $\hat{\chi}$ anymore, which doesn't change anything to the calculus and the results.

$$
\frac{\partial W^{P}}{\partial r_{i}}=\frac{\chi-\hat{\chi}}{\chi} \cdot \prod_{i}^{\prime}\left(r_{i} \pi_{i}\right)+(1-\hat{\chi}) \cdot\left[\left(r_{i}-1\right) M_{i}^{\prime}\left(r_{i}\right)+M_{i}\left(r_{i}\right)+S_{i}^{\prime}\left(r_{i}, \pi_{i}\right)\right]=0
$$

and (by Hotelling's lemma) ${ }^{6}$ :

$$
\frac{\chi-\hat{\chi}}{\chi} \cdot q_{i}+(1-\hat{\chi})\left(r_{i}-1\right) M_{i}^{\prime}\left(r_{i}\right)=-(1-\hat{\chi})\left(M_{i}\left(r_{i}\right)+S_{i}^{\prime}\left(r_{i}, \pi_{i}\right)\right)
$$

entailing:

$$
\left(r_{i}-1\right)=-\frac{(1-\hat{\chi})\left(M_{i}\left(r_{i}\right)+S_{i}^{\prime}\left(r_{i}, \pi_{i}\right)\right)+\frac{\chi-\hat{\chi}}{\chi} \cdot q_{i}}{(1-\hat{\chi}) \cdot M_{i}^{\prime}\left(r_{i}\right)}
$$

\footnotetext{
${ }^{5}$ Helpman considers that an individual's support of a tariff is an increasing function of the part of specific production he owns [15]. One may conclude that it's from the fraction (or concentration) of the factor of specific production owned that the benefit of the tariff is high enough to compensate the cost of collective action and to make the political organization of the owners of factors of specific production possible. It may be deduced in our framework that if the specific factor is unequally distributed, only those who own enough will see an interest in collective action $(\hat{\chi})$.
}

${ }^{6} \Pi_{i}\left(P_{i}\right)$ is the rent coming from the specific sector. With Hotelling's lemma (see for example [16], p. 680), we have: $\frac{\mathrm{d} \Pi_{i}}{\mathrm{~d} P_{i}}=q_{i}$; with $q_{i}$ the domestic quantity produced by sector $i$. The slope of the profit function is so the industry supply curve. 
This expression can be simplified. For one sector, the consumer surplus is:

$$
S_{i}\left(P_{i}\right)=U\left[d_{i}\left(P_{i}\right)\right]-P_{i} d_{i}\left(P_{i}\right)
$$

The surplus is derived in relation to the price:

$$
\frac{\mathrm{d} S_{i}}{\mathrm{~d} P_{i}}=d_{i}^{\prime}\left(P_{i}\right)\left[U^{\prime}\left[d_{i}\left(P_{i}\right)\right]-P_{i}\right]-d_{i}\left(P_{i}\right)
$$

A unit of standard good (price equal to 1) is produced with a labor unit, we have:

$$
U^{\prime}\left(d_{i}\left(P_{i}\right)-P_{i}\right)=0 \text {, entailing: } \frac{\mathrm{d} S_{i}}{\mathrm{~d} P_{i}}=-d_{i}
$$

We rewrite:

$$
\left(r_{i}-1\right)=-\frac{(1-\hat{\chi})\left(M_{i}\left(r_{i}\right)-d_{i}\right)+\frac{\chi-\hat{\chi}}{\chi} \cdot q_{i}}{(1-\hat{\chi}) \cdot M_{i}^{\prime}\left(r_{i}\right)}
$$

The imports correspond to demand minus supply, thus we have:

$$
\left(r_{i}-1\right)=\frac{\left(q_{i}\right)(\hat{\chi}(1-\chi))}{\chi \cdot(1-\hat{\chi}) \cdot M_{i}^{\prime}\left(r_{i}\right)}
$$

The optimal tariff for the population is:

$$
\left(r_{i}^{P}-1\right)=\frac{\left(q_{i}\right)}{M_{i}^{\prime}\left(r_{i}\right)} \cdot \frac{\hat{\chi}}{\chi} \cdot \frac{(1-\chi)}{(1-\hat{\chi})}
$$

$\left(r_{i}^{P}-1\right)$ is negative, which corresponds to an import subsidy or an export tax. In the absence of lobbies, not only will the population favor free trade (maximization of the consumer's surplus), but it may also wish the import prices to be diminished through a subsidy (on this issue see also [15]).

\subsection{Optimal Tariff for the Lobby}

We have:

$$
\begin{gathered}
W_{i}^{l}(r, \pi)=\hat{\chi} \cdot L_{i}+\frac{\hat{\chi}}{\chi} \cdot \prod_{i}\left(r_{i} \pi_{i}\right)+\hat{\chi} \cdot[R(r, \pi)+S(r, \pi)] \\
\frac{\partial W_{i}^{l}}{\partial r_{i}}=\frac{\hat{\chi}}{\chi} \cdot \prod_{i}^{\prime}\left(r_{i} \pi_{i}\right)+(\hat{\chi}) \cdot\left[\left(r_{i}-1\right) M_{i}^{\prime}\left(r_{i}\right)+M_{i}\left(r_{i}\right)+S_{i}^{\prime}\left(r_{i}, \pi_{i}\right)\right]=0
\end{gathered}
$$

entailing:

$$
\begin{gathered}
\left(r_{i}-1\right)=-\frac{\hat{\chi} \cdot\left(-q_{i}\right)+\frac{1}{\chi} \cdot q_{i}}{M_{i}^{\prime}\left(r_{i}\right)} \\
\left(r_{i}^{l}-1\right)=\frac{q_{i}\left(1-\frac{1}{\chi}\right)}{M_{i}^{\prime}\left(r_{i}\right)}
\end{gathered}
$$

which corresponds to the optimal tariff for the lobby. It's to be noted that the tariff depends only on the basic characteristics of the lobby and its sector: sector production, rigidity of the import demand and part of the interest group in relation to the whole population. The rigidity of the demand is a general principle in terms of taxes, applicable in the framework chosen here.

The part of the interest group in the population (which has a negative impact on the tariff level) comes under 
the Olsonian small size condition of creation and efficiency of the lobbies. The positive relation between the size of the industry and its tariff was highlighted relatively early ([17]). It's also present in Helpman [15], for whom the tariff is an increasing function of the volume of production of an industry (Helpman explains that a high production increases the stakes of protection) and it is also demonstrated by [18], specifying: "The positive firm size variable validates the notion that larger firms wield greater political influence because of their greater command over resources and more bargaining power with the government”.

This condition must not be mistaken for the one of the lobby's small size which concerns the number of specific factors owners, not the sector's output.

\subsection{The Tariff Applied}

$\left(r_{i}^{*}-1\right)$ is the tariff really applied. This tariff is a mix of the tariffs both the population and the lobby prefer (they are the two theoretical extremes).

We have: $\left(r_{i}^{l}-1\right)>\left(r_{i}^{*}-1\right)>\left(r_{i}^{P}-1\right)$.

In the framework of traditional political support, whether it be in terms of regulation in the manner of the approach Peltzman initiated ([5]) or in terms of election competition in the manner of the approach Brock and Magee initiated [19], the contributions are paid by the lobbies against tariffs so that the politicians may finance their campaigns and influence the voters' perception.

For the demonstration of the efficiency of lobbying, one can refer to [20]. The authors show that the firms which spend more on lobbying in a given year will pay less taxes the following one. Thus, on average for a firm, a $1 \%$ increase of lobbying costs decreases the effective rate of taxes in a range of $-0.5 \%$ to $-1.6 \%$.

For the evidence of the efficiency of campaigns on voters' choices, see [21].

We think here in terms of implicit contributions. The part of non informed voters is a proxy of the lobbies' influence (and of their interests being taken into account). Indeed the contributions are linked to the tariffs, but once we know which tariff the population and the lobby favor and we know the part of informed and non informed voters, we can deduce the tariff applied without having to formalize the contributions (which are the traditional conveyor of the influence of lobbying, this influence being directly appreciated by $(1-\alpha)$ ).

If all the voters are informed $(\alpha=1)$, the lobbies have no influence (and no justification-[22]). Then, $\left(r_{i}^{*}-1\right) \rightarrow\left(r_{i}^{P}-1\right)$.

Conversely, if all the voters are non-informed $(\alpha=0)$, then the lobbies have the upper hand, the voters are completely passive and $\left(r_{i}^{*}-1\right) \rightarrow\left(r_{i}^{l}-1\right)$.

The reality lies in-between and one considers that the more informed the voters, the more taken into accounts their preferences, according to a simple linear relation.

$G$ is the decision maker's objective function:

$$
G=\sum_{i}\left((1-\alpha) \cdot W_{i}^{l}+\alpha W_{i}^{P}\right) .
$$

One assumes, in the manner of Peltzman, that such a function exists for each sector, we have:

$$
G_{i}=(1-\alpha) \cdot W_{i}^{l}+\alpha W_{i}^{P}
$$

In the framework of implicit contributions, maximizing $G$ leads to the same solution as calculating $\left(r_{i}^{*}-1\right)$ from the following function:

$$
\left(r_{i}^{*}-1\right)=(1-\alpha) \cdot\left(r_{i}^{l}-1\right)+\alpha\left(r_{i}^{P}-1\right) .
$$

Then the endogenous tariff applied can be deduced:

$$
\left(r_{i}^{*}-1\right)=q_{i} \cdot \frac{(\chi-1)}{\chi} \cdot \frac{(\hat{\chi}+\alpha-1)}{M^{\prime}(\hat{\chi}-1)} .
$$

Thanks to this tariff a vector of trade policy can be expressed according (notably) to the part of specific factors owners in the population and according to the part of these owners who are organized into an active lobby.

We can observe that $\left(r_{i}^{*}-1\right)$ can be positive as well as negative. The tariff is positive when $(\hat{\chi}+\alpha-1)$ is negative. Then we have trade protection (not an import subsidy, for instance), when (for a given lobby), $\alpha<(1-\hat{\chi})$, i.e. when the part of informed voters is sufficiently low (informed voters being able to know how 
harmful a tariff is concerning their welfare). Under the $(1-\hat{\chi})$ threshold of informed voters, the lobbies have enough influence to impose a protection. This threshold will be all the higher (and a constraint) as the lobby is efficient (i.e. $\hat{\chi}$ is low).

The next section analyses in depth the properties of this endogenous tariff.

\section{Discussion}

First of all it can be noticed that the tariff the population favors is negative, which is logical since, were it not, the people concerned would be incited to organize in pressure groups, which fails to the other group considered by the model (who favors a positive tariff).

Thus it can be noticed that the more inflexible the import demand ( $M^{\prime}$ being low), the higher the tariff applied, which can be interpreted as follows. Supposing one measure lowers the well-being all the less because it's little distortive, then a lobby's demands will be all the more likely to be met because they are little distortive.

By reasoning on tariffs (distortions on prices) a lobby's action decreases the well-being all the less as the function of import demand is little flexible ${ }^{7}$.

A study of tariffs permits to confirm the standard results concerning the lobbies' creation and efficiency.

Thus we have $\frac{\partial r_{i}^{l}}{\partial \chi}=\frac{q_{i}}{\chi^{2} M^{\prime}}<0$, which is the Olsonian condition of the efficiency of collective action conditioned by the lobby's small size $e^{8}$ (see [14]). It can be noted here that the part of the lobby in the population $(\hat{\chi})$ doesn't impact the determination of the lobby's optimal tariff, contrary to the part of the interest group $(\chi)$, since, concerning the latter, the small size condition must be verified first so that the lobby may emerge and apply pressure in order to obtain a tariff.

Conversely we have, $\frac{\partial r_{i}^{P}}{\partial \chi}=\frac{q_{i} \hat{\chi}}{\chi^{2} M^{\prime}(\hat{\chi}-1)}>0$, which, by comparison with $\frac{\partial r_{i}^{l}}{\partial \chi}$, is a clear illustration of the antagonism between the lobbies and the population, this antagonism being itself the opposition between private and general interests ${ }^{9}$.

Among the well-known results, it can also be noted that the more inflexible the import demand, $\left(M^{\prime}\right.$ being low), the higher the tariff.

Mixing the two results relating to $\chi$ entails an applied tariff which decreases when the lobbies become less efficient $\left(\varepsilon_{r_{i}^{*} / \chi}=\frac{1}{\chi-1}<0\right)$; which has been a well-known result since Olson's work ([14]).

If one focuses on the sub-group of capital owners organized in lobby, we have:

$\frac{\partial r_{i}}{\partial \hat{\chi}}=(1-\chi) \cdot q_{i} \cdot \frac{\alpha}{M^{\prime} \chi(-1+\hat{\chi})^{2}}<0$. This derivative can be interpreted as a deeper Olsonian condition: even after the collective action has started, the lobby will be all the more efficient as its size is small. This can be explained by the increase of the per capita gain, which further incites to lobbying and to maintaining the Olsonian social pressure controlling the free rider comportment.

The part of informed voters is also factor of difference. We verify that $\frac{\partial r_{i}}{\partial \alpha}=(\chi-1) \cdot q_{i} \cdot \frac{\alpha}{M^{\prime} \chi(-1+\hat{\chi})}<0$. It means that when the part of informed voters increases, the tariff applied decreases: lesser influence of the lobbies on the population (informed voters being non influenceable), and lesser consideration by the decision maker for lobbies and the contribution they could provide. This result echoes a [26] study, which analyzes the role of demography in relation to trade policy in the field of political support.

The author shows that the choice to retire entails systematic effects on the voters' choice that they should be informed as well as on their preferences in relation to trade policies. This leads us to conclude that a life cycle

${ }^{7}$ On this point see, theoretically, [23] (p. 383), [7] (p. 842), and [15] (p. 6).

${ }^{8}$ Wellisz and Wilson believe that a group can reach its objectives even if its sole advantage is its small size ([24], p. 367, p. 372).

${ }^{9}$ For a historical example of the antagonism between private interests and collective well-being in the case of an endogenous trade policy, see [25]. The article shows how the American free-trade policy was damaged by the 1930 "Tariff Act", initiated by Willis Hawley (a congressman) and Reed Smoot (a senator), in spite of a petition to President Hoover signed by over a thousand American economists. 
effect does exist concerning the voters' preferences on trade policies.

Finally we study the role of the specific factor concentration/dispersion inside the interest group. This concentration is already important at the sector level, having facilitated the emergence of collective action (i.e. $\hat{\chi}$ is low). The stronger the concentration inside the potential lobby, the closer $\hat{\chi}$ to $\chi$.

$\beta$ is the concentration of specific factor, with $\beta=\frac{\hat{\chi}}{\chi}$. We show that when $\beta$ increases the tariff applied decreases ${ }^{10}$. It means that the higher number of factor owners in the pressure groups (and not in the lobby), the less efficient it is. This result can be explained if we consider that since the factor concentration (part of the lobby's members relative to the whole population) allowed collective action to emerge, this collective action will be all the more efficient as the actors mobilized are few in the group while the non mobilized actors still benefit from their passive free riding action.

The concentration effect inside the group outweighs the free riding it entails.

\section{Conclusions}

By focusing part of our reflection on the respective comportments of informed and non-informed voters, we make it possible to simplify Grossman and Helpman's model by considering "implicit" contributions (present but not formalized).

The model makes it possible to deduce the endogenous tariff applied by the decision maker according to the relative force of informed voters. This tariff has the properties expected, notably the Olsonian condition of efficiency through a small size.

Making a distinction between an interest group and its part organized as a lobby makes it possible to show that the applied tariff has properties in terms of free riding comportment: it is being possibly counterbalanced by the greater efficiency of a higher concentration of specific factors owners. Let's note that free riding itself is here of a particular nature in the sense that the strong concentration of the lobby's members inside the interest group entails mechanical free riding, which does not imply a strategic comportment on the free riders' part: indeed they benefit from the tariff, but the part of specific factor they own doesn't generate a rent amount higher for them than the cost of collective action.

By differentiating the specific factors owners and the part of the specific factors owners organized in a lobby, the Olsonian condition can be seen as a two-step process for the lobbies' formation and efficiency. On the one hand, the small size of the specific factors owners allows limiting free riding and permits collective action, then once collective action is effective, a second manifestation of the small size appears (when considering the small size of the lobby within the interest group). It creates de facto free riding, albeit unable to threaten neither the lobby's existence nor its efficiency.

It is also shown that the tariff applied decreases with the part of informed voters. Since a "life cycle" factor has been identified concerning the voters' preferences on trade policies (see above [26]), the model will also permit to formalize this life cycle by making the part of informed voters endogenous according to the age pyramid in the population.

\section{Acknowledgements}

Financial support from the Fonds Pacifique of the French Overseas Ministries is gratefully acknowledged. The usual disclaimer applies.

\section{References}

[1] Buchanan, J.M. and Tullock, G. (1962) The Calculus of Consent: Logical Foundations for Constitutional Democracy. The University of Michigan Press, Michigan.

[2] Horgos, D. and Zimmermann, K.W. (2009) Interest Groups and Economic Performance: Some New Evidence. Public Choice, 138, 301-315. http://dx.doi.org/10.1007/s11127-008-9360-4

[3] Laband, D.N. and Sophocleus, J.P. (1988) The Social Cost of Rent-Seeking: First Estimates. Public Choice, 58, 269-

${ }^{11}$ Indeed we have: $\frac{\partial r_{i}}{\partial \beta}=(1-\chi) \cdot q_{i} \cdot \frac{\alpha}{M^{\prime}(-1+c \chi)^{2}}<0$. 
275. http://dx.doi.org/10.1007/BF00155672

[4] Baldwin, R.E. (1982) The Political Economy of Protectionism. In: Bhagwati, J.N., Ed., Import Competition and Response, University of Chicago Press, Chicago, 263-292.

[5] Peltzman, S. (1976) Toward a More General Theory of Regulation. The Journal of Law and Economics, 19, $211-248$. http://dx.doi.org/10.1086/466865

[6] Hillman, A.L. (1982) Declining Industries and Political-Support Protectionist Motives. American Economic Review, 72 , 1180-1187.

[7] Grossman, G. and Helpman, E. (1994) Protection for Sale. American Economic Review, 84, 833-850.

[8] Grossman, G. and Helpman E. (1995a) The Politics of Free-Trade Agreements. American Economic Review, 85, 667-690.

[9] McCalman, P. (2004) Protection for Sale and Trade Liberalization: An Empirical Investigation. Review of International Economics, 12, 81-94. http://dx.doi.org/10.1111/j.1467-9396.2004.00432.x

[10] Baron, D.P. (1994) Electoral Competition with Informed and Uninformed Voters. American Political Science Review, 88, 33-47. http://dx.doi.org/10.2307/2944880

[11] Ansolabehere, S., de Figueiredo, J.M. and Snyder Jr, J.M. (2003) Why Is There So Little Money in US Politics. Journal of Economic Perspectives, 17, 105-130. http://dx.doi.org/10.1257/089533003321164976

[12] Desai, R.M. and Olofsgard, A. (2011) The Costs of Political Influence: Firm-Level Evidence From Developing Countries. Quarterly Journal of Political Science, 6, 137-178. http://dx.doi.org/10.1561/100.00010094

[13] Wenegast, T. (2010) Uninformed Voters for Sale: Electoral Competition, Information and Interest Groups in the US. Kyklos, 63, 271-300. http://dx.doi.org/10.1111/j.1467-6435.2010.00473.x

[14] Olson, M. (1966) The Logic of Collective Action. Harvard University Press, Cambridge.

[15] Helpman, E. (1995) Politics and Trade Policy. NBER Working Papers Series, 5309, 36.

[16] Grossman, G. and Helpman, E. (1995-b) Trade Wars and Trade Talks. Journal of Political Economy, 103, $675-708$. http://dx.doi.org/10.1086/261999

[17] Pincus, J.J. (1975) Pressure Groups and the Pattern of Tariffs. Journal of Political Economy, 83, 757-778. http://dx.doi.org/10.1086/260354

[18] Yasar, M., Rejesus, R.M., Chen, Y. and Chakravorty, U. (2011) Political Influence of Firms in the Tradables and NonTradables Sectors: A Cross-Country Analysis. Economics \& Politics, 23, 297-312. http://dx.doi.org/10.1111/j.1468-0343.2011.00386.x

[19] Brock, W.A. and Magee, S.P. (1978) The Economics of Special Interest Politics: The Case of the Tariff. American Economic Association Papers and Proceedings, 68, 246-250.

[20] Richter, B.K., Samphantharak, K. and Timmons, J.F. (2009) Lobbying and Taxes. American Journal of Political Science, 53, 893-909. http://dx.doi.org/10.1111/j.1540-5907.2009.00407.x

[21] Arceneaux, K. and Huber, G.H. (2007) Identifying the Persuasive Effects of Presidential Advertising. American Journal of Political Science, 51, 957-977. http://dx.doi.org/10.1111/j.1540-5907.2007.00291.x

[22] Black, D. (1958) The Theory of Committees and Elections. Cambridge University Press, Cambridge.

[23] Becker, G.S. (1983) A Theory of Competition among Pressure Groups for Political Influence. Quarterly Journal of Economics, 98, 371-400. http://dx.doi.org/10.2307/1886017

[24] Wellisz, S. and Wilson, J.D. (1986) Lobbying and Tariff Formation: A Deadweight Loss Consideration. Journal of International Economics, 20, 367-375. http://dx.doi.org/10.1016/0022-1996(86)90028-0

[25] The Economist (2008) The Battle of Smoot-Hawley. Finance \& Economics, 4.

[26] Bloningen, B. (2008) New Evidence on the Formation of Trade Policy Preferences. NBER Working Papers No. 14627. 